\title{
PENGARUH PENDEKATAN KONFLIK KOGNITIF TERHADAP PENGUASAAN KONSEP FISIKA PESERTA DIDIK
}

\author{
Martina Nur Larasafitri*, Sutrio, Gunawan \\ Program Studi Pendidikan Fisika, Universitas Mataram \\ *Email: martina.nur.larasafitri@gmail.com
}

\begin{abstract}
This research aimed at measure the effect of cognitive conflict approach on the mastery of physics concept of students. Cognitive conflict is an approach consisting of preliminary, conflict, and settlement phases. This quasi-experimental research uses non-equivalent group design. The population of this research was all XI IPA students of SMAN 6 Mataram in academic year 2017/2018. The sample was chosen using cluster random sampling, with XI IPA 1 as experiment class and XI IPA 2 as control class. The instrument used for concept mastery refers to students cognitive abilities $\left(C_{1}, C_{2}, C_{3}, C_{4}, C_{5}\right.$, $\left.C_{6}\right)$. Hypothesis test using t pooled varians. The improvement of concept mastery is determined based on the results of the $n$-gain test. The results of research indicate the influence of cognitive conflict approach on the mastery of physics concept of students. In addition, the experimental class experienced an increased mastery concept higher than control class. This suggests the cognitive conflict approach applied successfully improves the mastery of the physics concepts of students, especially on sub material nature of material elasticity, Hooke law, and the arrangement of springs.
\end{abstract}

Keywords: Cognitive Conflict Approach, Mastery of Physics Concept.

\section{PENDAHULUAN}

Pendidikan merupakan hal yang penting bagi suatu bangsa, karena tanpa pendidikan suatu bangsa tidak akan maju dan berkembang. Apabila sistem pendidikan itu baik, bermutu dan berkualitas, akan terbentuk bangsa yang berperadaban tinggi, sebaliknya jika sistem pendidikannya kurang baik, kurang bermutu dan kurang berkualitas bangsa itu akan terbelakang. Ilmu pengetahuan alam (IPA) merupakan ilmu yang berkaitan dengan cara mencari tahu tentang alam secara sistematis sehingga IPA bukan hanya penguasaan kumpulan pengetahuan berupa fakta-fakta, konsepkonsep, atau prinsip-prinsip saja, tetapi juga merupakan suatu proses penemuan (Fitriani et al., 2017).

Fisika merupakan salah satu cabang ilmu pengetahuan alam yang terdiri dari konsep, prinsip, teori dan atau hukum terkait dengan gejala-gejala alam yang ada (Helmi et al., 2017). Pembelajaran fisika harus diarahkan untuk mencari tahu dan berbuat sehingga dapat membantu peserta didik untuk memperoleh penguasaan yang lebih mendalam, oleh sebab itu, pembelajaran fisika harus menekankan pada pemberian pengalaman langsung dan berpusat pada siswa. Sesuai dengan isi Permendiknas No.22 Tahun 2006, salah satu tujuan pembelajaran fiika adalah menguasai konsep.

Dahar (2011), menyebutkan bahwa belajar konsep merupakan hasil utama pendidikan. Dengan demikian, perlu dikembangkan tingkat penguasaan konsep peserta didik dalam pembelajaran fisika. Penguasaan konsep fisika merupakan salah satu aspek dalam mengukur hasil belajar siswa yang didapat guna mewujudkan pembelajaran (Sugiana et al., 2016).

Gunawan et al., (2014) menyatakan bahwa beberapa konsep fisika termasuk konsep yang abstrak. Konsep fisika yang abstrak sering kali menjadi kendala bagi guru dalam menyampaikan materi kepada siswa, sehingga siswa belum optimal dalam memahami konsep yang dijelaskan guru. Hal ini tentunya berdampak pada minat 
belajar siswa dalam menerima pelajaran fisika yang menyebabkan rendahnya penguasaan konsep siswa untuk menyelesaikan suatu persoalan. Pentingnya seseorang menguasai suatu konsep adalah agar ia mampu berkomunikasi, mengklasifikasikan ide, gagasan atau peristiwa yang dialaminya dalam kehidupan sehari-hari (Suranti et al., 2016).

Berdasarkan hasil observasi dan wawancara dengan siswa dan guru mata pelajaran fisika kelas XI SMAN 6 Mataram, bahwa mata pelajaran fisika sering dianggap sebagai pelajaran yang sulit dan membosankan. Hal ini sejalan dengan pendapat Setyowati et al., (2011) yang mengatakan bahwa mata pelajaran fisika dirasakan sulit oleh siswa, karena sebagian besar siswa belum mampu menghubungkan antara materi yang dipelajari dengan pengetahuan yang digunakan. Siswa lebih sering langsung menggunakan persamaan matematis tanpa melakukan analisis, menebak rumus yang digunakan dan menghafal contoh soal yang telah dikerjakan untuk mengerjakan soal-soal lain (Kusdiastuti et al., 2016).

Masalah ini akan membawa pola pikir siswa pada pembelajaran sangat monoton, di samping itu guru dalam proses pembelajaran kurang memperhatikan konsep awal siswa. Selain itu, penggunaan sistem pembelajaran yang tradisional yaitu dengan metode ceramah sehingga peserta didik menerima pengetahuan secara abstrak tanpa mengalami sendiri. Mata pelajaran fisika erat kaitannya antara konsep dan lingkungan sekitar, tetapi peserta didik belum bisa mengaplikasikannya secara langsung.

Akibatnya, penguasaan konsep siswa menjadi rendah. Kurangnya penguasaan konsep fisika ditunjukkan dengan rendahnya hasil belajar fisika peserta didik. Masalah ini dapat diatasi salah satunya dengan pendekatan konflik kognitif.
Penelitian-penelitian sebelumnya menunjukkan pengaruh konflik kognitif dalam pembelajaran. Hasil penelitian Tuqalby et al., (2017) menunjukkan konflik kognitif dalam pembelajaran dapat meningkatkan penguasaan konsep lebih tinggi dari model konvensional. Hasil penelitian Fatimah et al., (2016) menunjukkan konflik kognitif dalam pembelajaran dapat mempengaruhi penguasaan konsep dan kemampuan berpikir kritis.

Berdasarkan kenyataan tersebut di atas, maka perlu dilakukan perbaikan dalam kegiatan pembelajaran agar penguasaan konsep fisika siswa dapat meningkat. Salah satu alternatif pemecahan masalahnya adalah dengan menggunakan pendekatan konflik kognitif. Berdasarkan uraian di atas, peneliti tertarik untuk melakukan penelitian berjudul "Pengaruh Pendekatan Konflik Kognitif Terhadap Penguasaan Konsep Fisika dan Keterampilan Berpikir Kritis Peserta Didik".

\section{METODE PENELITIAN}

Jenis penelitian yang digunakan adalah penelitian kuasi eksperimen dengan desain non-equivalent group design. Sebelum diberi perlakukan kedua kelompok sampel diberikan tes awal untuk mengukur kondisi awal. Selanjutnya kelas eksperimen diberikan perlakuan dengan pendekatan konflik kognitif dan kelas kontrol diberi perlakuan berupa model pembelajaran konvensional (direct instruction). Sesudah perlakuan, kedua kelas diberikan tes akhir.

Dalam penelitian ini ada 3 variabel yaitu variabel bebas yaitu pendekatan konflik kognitif, variabel terikat yaitu penguasaan konsep fisika, variabel kontrol yaitu materi ajar yang diajarkan, guru yang mengajar, dan instrumen penilaian pada kelas eksperimen dan kontrol. Populasi dalam penelitian ini adalah seluruh siswa kelas XI IPA di SMAN 6 Mataram tahun 
ajaran 2017/2018 yang berjumlah 4 kelas. Sedangkan sampel adalah bagian dari populasi. Sampel yang digunakan dipilih dengan menggunakan teknik cluster random sampling. Penelitian ini, untuk mengukur penguasaan konsep digunakan tes berupa pilihan ganda sebanyak 30 soal. Sebelumnya tes pilihan ganda di uji validitasnya sehingga diperoleh 30 soal yang valid. Uji $F$ digunakan untuk mengetahui homogenitas data dan uji normalitas untuk mengetahui apakah data terdistribusi normal atau tidak. Setelah itu, untuk mengetahui pengaruh pendekatan konflik kognitif terhadap penguasaan konsep dilakukan uji hipotesis dengan uji $t$ pooled varians. Selain uji hipotesis, dilakukan juga uji N-Gain.

\section{HASIL DAN PEMBAHASAN}

Berdasarkan ranah yang dinilai, yaitu ranah kognitif, maka kemampuan yang diukur adalah kemampuan kognitif penguasaan konsep siswa. Tes yang diberikan adalah tes tertulis berbentuk pilihan ganda yang terdiri dari 30 soal. Adapun penguasaan konsep siswa sebelum diberikan perlakuan terlihat dari nilai tes awalnya (pre-test), dan penguasaan konsep setelah diberikan perlakuan terlihat dari nilai tes akhir (pos-test).

Tes awal dilakukan untuk mengetahui homogenitas serta normalitas sampel. Adapun hasil tes awal dapat dilihat pada tabel 1. Pada hasil tes awal, nilai tertinggi untuk kelas eksperimen adalah 83 dan kelas kontrol adalah 73 sedangkan untuk nilai terendah pada kelas eksperimen adalah 47 dan pada kelas kontrol 37. Dengan ratarata nilai kelas eksperimen 62.45 dan ratarata nilai kelas kontrol 53.25.

Data kemampuan akhir diperoleh pada penelitian ini setelah diberikan perlakuan. Tes akhir diberikan untuk mengetahui normalitas dan hipotesis penelitian. Adapun hasil tes akhir dapat dilihat pada Tabel 1. Pada hasil tes akhir, nilai tertinggi untuk kelas eksperimen adalah 97 dan kelas kontrol adalah 83 sedangkan untuk nilai terendah pada kelas eksperimen adalah 70 dan pada kelas kontrol 57. Dengan rata-rata nilai kelas eksperimen 84.61 dan rata-rata nilai kelas kontrol 67,02.

Tabel 1 Hasil Penguasaan Konsep Kelas Eksperimen dan Kelas Kontrol

\begin{tabular}{cccccc}
\hline Kelas & Kemampuan & $\begin{array}{c}\text { Jumlah } \\
\text { Peserta didik }\end{array}$ & Nilai tertinggi & Nilai terendah & Rata-rata \\
\hline Eksperimen & \multirow{2}{*}{ Awal } & 34 & 83 & 47 & 62.45 \\
Kontrol & & 38 & 73 & 37 & 53.25 \\
Eksperimen & \multirow{2}{*}{ Akhir } & 34 & 97 & 70 & 84.61 \\
Kontrol & & 38 & 83 & 57 & 67.02 \\
\hline
\end{tabular}

Pengujian data penguasaan konsep siswa untuk kelas eksperimen dan kelas kontrol tes awal dan tes akhir diawali dengan uji homogenitas kedua data, yang dilanjutkan dengan uji normalitas, dan terakhir uji hipotesis menggunakan uji-t polled varians. Dari uji homogenitas data untuk tes awal yang telah dilakukan didapat hasil nilai $F_{\text {hitung }}$ sebesar 1,34 sedangkan nilai $F_{\text {tabel }} 1,78$ dengan taraf signifikan 0,05 .
Sehingga $F_{\text {hitung }}<F_{\text {tabel yang berarti data tes }}$ awal kedua kelas adalah homogen.

Selanjutnya dilakukan uji normalitas data tes awal dan tes akhir pada masingmasing kelas. Berdasarkan perhitungan yang telah dlakukan didapatkan hasil bahwa data berdistribusi normal pada tes awal dan tes akhir untuk kelas eksperimen dan kelas kontrol. Untuk tes awal didapatkan nilai $\chi_{\text {hitung }}^{2}$ sebesar 9.90 untuk kelas eksperimen dan 9.72 untuk kelas kontrol. 
Nilai $\chi_{\text {tabel }}^{2}$ dengan taraf signifikan 0,05 untuk kelas eksperimen dan kelas kontrol sebesar 11.07. Sehingga dari kedua data tersebut dapat dilihat bahwa $\chi_{\text {hitung }}^{2}$ $\chi_{\text {tabel }}^{2}$ yang berarti data tes awal untuk kedua kelas berdistribusi normal. Sedangkan untuk tes akhir nilai $\chi^{2}{ }_{\text {hitung }}$ untuk kelas eksperimen sebesar 9.32 dan untuk kelas kontrol sebesar 10.36 Nilai $\chi_{\text {tabel }}^{2}$ dengan taraf signifikan 0,05 untuk kedua kelas adalah 11.07 sehingga data tes akhir kedua kelas terdistribusi normal.

Untuk mengetahui adanya pengaruh pendekatan konflik kognitif terhadap penguasaan konsep fisika peserta didik dilakukan uji hipotesis. Uji hipotesis menggunakan statistik paramtrik karena data homogen dan terdistribusi normal. Uji hipotesis yang digunakan adalah uji-t polled varians karena sampel pada penelitian ini berbeda $\left(n_{1} \neq n_{2}\right)$. Hasil uji statistik yang dilakukan didapatkan nilai thitung sebesar 12.09. Nilai thitung tersebut lebih besar dibandingkan nilai $t_{\text {tabel, }}$ yaitu 1,993 pada taraf signifikan 0,05 . Sehingga penggunaan pendekatan konflik kognitif berpengaruh terhadap penguasaan konsep fisika peserta didik. Penguasaan konsep fisika dapat meningkat melalui pendekatan konflik kogitif karena peserta didik dihadapkan langsung pada situasi yang bertentangan dengan konsepnya, kemudian di arahkan pada percobaan atau demonstrasi untuk membuktikan kebenaran konsep tersebut. Dalam pembelajaran ini siswa diberikan kesempatan untuk mengungkapkan konsepsinya dan mengkritisi yang berbeda dengan konsepsinya. Dengan terlibat langsung dalam proses pembelajaran peserta didik dapat menguasai konsep fisika dengan baik. Hasil ini juga diperkuat dengan hasilhasil penelitian sebelumnya mengenai pendekatan konflik kognitif. Setyowati et al., (2011) menyatakan bahwa konfklik kognitif dalam pembelajaran fisika pada materi tekanan mampu menumbuhkan kemampuan berpikir kritis, penguasaan konsep dan hasil belajar kognitif siswa. Selain itu penelitian Baser (2006) \& Sirait (2012) menyatakan bahwa konflik kognitif dapat meningkatkan penguasaan konsep fisika siswa lebih signifikan dibandingkan dengan model konvensional. Hasil-hasil tersebut memperkuat hasil penelitian ini, yaitu adanya pengaruh pendekatan konflik kognitif terhadap penguasaan konsep fisika peserta didik.

Gambar 1. Perbandingan Nilai Ngain(\%) Per Sub Materi

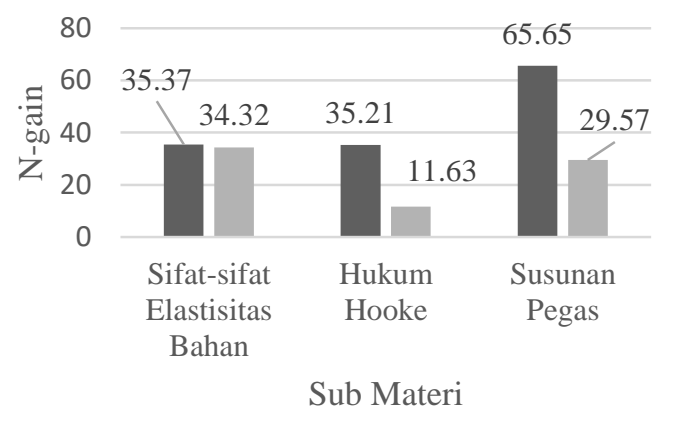

- Kelas Eksperimen Kelas Kontrol

Selain melakukan uji hipotesis peneliti juga ingin mengetahui sejauh mana peningkatan yang dialami kedua kelas secara lebih terperinci terkait hubungan nilai kelas kontrol dan kelas eksperimen untuk persentase kenaikan penguasaan konsep. Perbandingan peningkatan penguasaan konsep per sub materi elastisitas dalam Gambar 1. Materi elastisitas terbagi kedalam 3 sub materi yaitu tekanan sifat elastisitas bahan, hukum Hooke, dan susunan pegas. Setiap sub materi dianalisis ketercapaiannya berdasarkan perolehan skor tes awal dan tes akhir dan gain ternormalisasi. Perbandingan peningkatan penguasaan konsep per sub materi elastisitas dalam Gambar 1. 
Berdasarkan analisis pada Gambar 1 dapat diketahui bahwa perolehan Persentase $\mathrm{N}$-gain tertinggi kelas eksperimen, yaitu pada sub materi Susunan Pegas $65.65 \%$ dan terendah sebesar $35.21 \%$ pada sub materi Hukum Hooke. Sedangkan pada kelas kontrol $\mathrm{N}$-gain tertinggi adalah $34.32 \%$ pada sub materi sifat-sifat elastisitas bahan dan terendah pada sub materi hukum Hooke $11.63 \%$. Secara rata-rata, peningkatan penguasaan konsep fisika pada kelas eksperimen lebih tinggi dibandingkan kelas kontrol. Dimana pada kelas eksperimen ratarata peningkatannya sebesar $49.30 \%$ sedangkan peningkatan kelas kontrol adalah $25.16 \%$.

\section{KESIMPULAN DAN SARAN}

Berdasarkan hasil dan pembahasan yang telah dipaparkan dapat disimpulkan bahwa pendekatan konflik kognitif berpengaruh terhadap penguasaan konsep fisika peserta didik. Adapun saran yang dapat diberikan bagi guru fisika pendekatan konflik kognitif dapat dijadikan alternative dalam mengajar fisika. Namun, dalam penerapannya memerlukan perencanaan dan persiapan yang matang sebelum diterapkan di kelas agar proses pembelajaran dapat berjalan sesuai dengan tujuan pembelajaran yang hendak dicapai. Sedangkan untuk penelitian selanjutnya, pendekatan konflik kognitif dapat dilakukan pada materi yang berbeda dengan subjek peneliitian yang lebih luas.

\section{REFERENSI}

Baser, M. (2006). Fostering conceptual change by cognitive conflict based instruction on students' understanding of heat and temperature concepts. Eurasia Journal of Mathematics, Science and Technology Education, 2(2), 96-114.
Dahar, W. R. 2011. Teori-teori Belajar Belajar dan Pembelajaran. Bandung: Erlangga.

Fatimah, N., Gunawan, G., \& Wahyudi, W. (2017). Pembelajaran Berbasis Masalah Dengan Strategi Konflik Kognitif Terhadap Penguasaan Konsep Dan Kemampuan Berpikir Kritis Fisika Siswa Kelas XI SMKN 1 Lingsar Tahun Pelajaran 2015/2016. Jurnal Pendidikan Fisika dan Teknologi, 2(4), 183-190.

Fitriani, N., Gunawan, G., \& Sutrio, S. (2017). Berpikir Kreatif dalam Fisika dengan Pembelajaran Conceptual Understanding Procedures (CUPs) berbantuan LKPD. Jurnal Pendidikan Fisika dan Teknologi, 3(1), 24-33.

Gunawan, G., Setiawan, A., \& Widyantoro, D. H. (2014). Model Virtual Laboratory Fisika Modern untuk Meningkatkan Keterampilan Generik Sains Calon Guru. Jurnal Pendidikan dan Pembelajaran (JPP), 20(1), 25-32.

Helmi, F., \& Rokhmat, J. (2017). Pengaruh Pendekatan Berpikir Kausalitik Berscaffolding Tipe 2b Termodifikasi Berbantuan Lks Terhadap Kemampuan Pemecahan Masalah Fluida Dinamis Siswa. Jurnal Pendidikan Fisika dan Teknologi, 3(1), 68-75.

Kusdiastuti, M., Harjono, A., Sahidu, H., \& Gunawan, G. (2017). Pengaruh Model Pembelajaran Inkuiri Berbantuan Laboratorium Virtual Terhadap Penguasaan Konsep Fisika Peserta Didik. Jurnal Pendidikan Fisika dan Teknologi, 2(3), 116-122.

Setyowati, A., \& Subali, B. (2011). Implementasi pendekatan konflik kognitif dalam pembelajaran fisika untuk menumbuhkan kemampuan berpikir kritis siswa SMP kelas VIII. Jurnal Pendidikan Fisika Indonesia, $7(2)$. 
Sirait, J. (2012). Pendekatan Pembelajaran Konflik Kognitif Untuk Meningkatkan Penguasaan Konsep Siswa SMA pada Topik Suhu dan Kalor. Jurnal Pendidikan Matematika dan IPA, 1(2).

Sugiana, I. N., Harjono, A., Sahidu, H., \& Gunawan, G. (2017). Pengaruh Model Pembelajaran Generatif Berbantuan Media Laboratorium Virtual Terhadap Penguasaan Konsep Fisika Siswa pada Materi Momentum dan Impuls. Jurnal Pendidikan Fisika dan Teknologi, 2(2), 61-65.

Suranti, N. M. Y., Gunawan, G., \& Sahidu, H. (2017). Pengaruh Model Project Based Learning Berbantuan Media Virtual Terhadap Penguasaan Konsep Peserta didik pada Materi Alat-alat Optik. Jurnal Pendidikan Fisika dan Teknologi, 2(2), 73-79.

Tuqalby, R., Sutrio, S., \& Gunawan, G. (2017). Pengaruh Strategi Konflik Kognitif Terhadap Penguasaan Konsep Pada Materi Fluida Siswa Sman 3 Mataram Tahun Ajaran 2016/2017. Jurnal Pendidikan Fisika dan Teknologi, 3(1), 8-13. 